\title{
RNA polymerase II carboxy-terminal domain contributes to the response to multiple acidic activators in vitro
}

\author{
Sha-Mei Liao, ${ }^{1}$ Ian C.A. Taylor, ${ }^{2}$ Robert E. Kingston, ${ }^{2}$ and Richard A. Young ${ }^{1}$ \\ ${ }^{1}$ Whitehead Institute for Biomedical Research, Cambridge, Massachusetts 02142 USA and Department of Biology, \\ Massachusetts Institute of Technology, Cambridge, Massachusetts 02142 USA; $^{2}$ Department of Molecular Biology, \\ Massachusetts General Hospital, Boston, Massachusetts 02114 USA and Department of Genetics, Harvard Medical School, \\ Boston, Massachusetts 02115 USA
}

\begin{abstract}
The largest subunit of RNA polymerase II contains a unique carboxy-terminal domain (CTD) that consists of repeats of the heptapeptide YSPTSPS. RNA polymerase II CTD truncation mutations affect the ability to induce transcription of a subset of yeast genes in vivo, and the lack of response to induction maps to the upstream activating sequences of these genes. Here, we report that progressive truncation of the yeast RNA polymerase II CTD causes progressive loss of trans-activator-dependent transcription in nuclear extracts but has little effect on elongation or termination. Specific transcription, which is reduced by up to 50 -fold in these assays, can be restored in the defective nuclear extracts by adding purified wild-type RNA polymerase II. The defects in factor-dependent transcription are observed with templates that are assembled into nucleosomes as well as with templates that are not so assembled. Defects in factor-independent transcription are also observed, but these are not as profound as those observed in the presence of trans-activators. These results indicate that the RNA polymerase II CTD functions during transcription initiation and is required for normal levels of activated transcription in vitro.
\end{abstract}

[Key Words: RNA polymerase II; carboxy-terminal domain; transcription initiation]

Received September 5, 1991; revised version accepted October 23, 1991.

The largest subunit of eukaryotic nuclear RNA polymerase II has an unusual carboxy-terminal domain (CTD) containing tandem heptapeptide repeats of the consensus sequence Tyr-Ser-Pro-Thr-Ser-Pro-Ser (Allison et al. 1985, 1988; Corden et al. 1985; Falkenburg et al. 1987; Zehring et al. 1988; Bird and Riddle 1989; Dietrich et al. 1990; for reviews, see Corden 1990; Chao and Young 1991). In general, the more complex the eukaryotic species are, the larger the number of repeats found in the CTD. The RNA polymerase II CTD is essential for eukaryotic cell viability (Nonet et al. 1987; Allison et al. 1988; Bartolomei et al. 1988; Zehring et al. 1988). CTD partial deletions can produce cold-sensitive and temperature-sensitive growth defects in yeast and cause cells to lose the ability to grow on a variety of carbon sources (Nonet et al. 1987; Nonet and Young 1989). A subset of the RNA polymerase II molecules in yeast and in mammalian cells have highly phosphorylated CTDs (Cadena and Dahmus 1987; Kolodziej et al. 1990), and phosphorylation of the CTD appears to occur during initiation (Laybourn and Dahmus 1989, 1990; for review, see Dahmus and Dynan 1991).

The RNA polymerase II CTD has been implicated in the response of the transcription apparatus to regulatory signals at certain promoters in vivo (Allison and Ingles
1989; Scafe et al. 1990; Peterson et al. 1991). In yeast, there is a significant reduction in the ability to induce transcription of specific genes, such as INO1 and GAL10, when the CTD is truncated from 27 to 11 repeats (Scafe et al. 1990). The gene-specific defects are dependent on certain upstream activating sequences (UASs). In CTD truncation mutants, the relative ability to transcribe INO1, GAL10, and HIS4 upon induction precisely parallels the relative response of the transcription apparatus to the INO1, GAL10, and HIS4 UAS elements. Both positive and negative regulatory proteins have been implicated in the CTD-dependent effects. CTD truncation magnifies transcriptional defects in a variety of GAL4 activation mutants, whereas extension of the CTD suppresses these defects (Allison and Ingles 1989). Elimination of at least one negative regulatory factor, SIN1, can partially suppress transcriptional defects, due to CTD truncation (Peterson et al. 1991).

RNA polymerase II CTD function has been investigated in transcription assays in vitro by using antibody or synthetic peptide inhibitors and by using RNA polymerase II preparations in which the CTD has been removed by proteolysis (Kim and Dahmus 1989; Moyle et al. 1989; Thompson et al. 1989). In one series of experiments, monoclonal antibodies directed against the CTD 
were found to inhibit transcription initiation in crude extracts at both the adenovirus 2 major late and the dihydrofolate reductase (DHFR) promoters. Although purified mammalian RNA polymerase II could restore transcription from both of these promoters, RNA polymerase II lacking the CTD could initiate transcription only from the adenovirus promoter (Thompson et al. 1989). Extension of these experiments has revealed that approximately half of the mammalian promoters tested could not be transcribed by RNA polymerase II lacking the CTD (A.B. Buermeyer and P.J. Farnham, pers. comm.). These in vitro experiments, like the in vivo experiments in yeast, suggest that the contribution of the CTD differs substantially with different genes.

To better understand the role of RNA polymerase II CTD in transcription, we investigated the ability of yeast nuclear extracts containing a spectrum of CTD truncation mutations to initiate, elongate, and terminate RNAs using specific DNA templates. Our results demonstrate that progressive RNA polymerase II CTD truncation progressively and substantially reduces selective initiation at two promoters dependent on acidic activating factors but does not significantly alter elongation or termination.

\section{Results}

\section{CTD truncation reduces factor-dependent transcription}

The effect of CTD truncation on promoter-dependent transcription in vitro was assayed using nuclear extracts from wild-type yeast cells and from cells containing a series of CTD partial deletion mutations (Fig. 1A). By using a template containing a hybrid promoter consisting of a GAL4-binding site and a CYCl TATA element, pGAL4CG ${ }^{-}$(Fig. 1B), the levels of GAL4-VP16-stimulated RNA polymerase II transcripts were measured. The amount of specific transcript produced in the nuclear extracts dropped substantially with reduced CTD length (Fig. 1C). When CTD lengths were reduced to 17, 14, 13, and 11 repeats, the levels of specific transcript produced in the extracts were $58 \%, 8 \%, 5 \%$, and $2 \%$, respectively, of that in the wild-type extract. Template topology did not influence this result; the levels of transcripts were similarly reduced with linear or circular template DNA (not shown). Thus, progressive truncation of the RNA polymerase II CTD results in a substantial and progressive loss in GAL4-VP16-dependent transcripts from the GAL4-CYCl hybrid promoter.

The effect of CTD truncation on transcription of a second template, pCZ3GAL, was investigated to confirm these results and to ensure that they are not the result of artifacts introduced through the presence of the $\mathrm{G}^{-}$region in the pGAL4CG ${ }^{-}$template. This template contains a hybrid $\mathrm{CYCl}$ promoter with three GAL4-binding sites and a CYC1 TATA, but lacks the $\mathrm{G}^{-}$region/Chasman et al. 1989|. The results of this experiment were identical to those obtained with the other hybrid promoter template: Primer extension analysis revealed that progressive CTD truncation caused a progressive and significant decrease in GAL4-VP16 dependent transcripts (data not shown).
Figure 1. Progressive truncation of the RNA polymerase II CTD causes progressive loss of GAL4-VP16-stimulated transcription. $\{A \mid$ The number of carboxy-terminal repeats in each of the yeast strains is shown diagrammatically. Strain L14 contains an RPB1 gene with the wild-type 27 heptapeptide repeats; V7 has $174 / 7$ repeats, V20 has $145 / 7$ repeats, V17 has $134 / 7$ repeats, and C6 has $113 / 7$ repeats. For simplicity, we refer to the mutants in the text by the number of complete repeats in their CTDs. $(B)$ The DNA template pGAL4CG $^{-}$contains a yeast $\mathrm{CYCl}$ promoter lacking its normal UAS but containing a 17-bp GAL4-binding site upstream of the $\mathrm{CYCl}$ maior TATA box; the 377 bp downstream of the $\mathrm{CYCl}$ promoter lacks $\mathrm{G}$ residues (the $\mathrm{G}^{-}$ region) on the sense strand (Lue et al. 1989). Transcription from this hybrid $\mathrm{CYCl}$ promoter is initiated within the $\mathrm{G}^{-}$region and results in the synthesis of RNA species which, after RNase T1 treatment, are $\sim 350$ and 375 nucleotides long. Supercoiled template was used in the transcription reactions. $(C)$ GAL4-VP16 protein-dependent transcription was performed in 25- $\mu$ l reactions containing $0.25 \mu \mathrm{g}$ of template DNA $(0.13 \mathrm{pmole}), 0.15 \mu \mathrm{g}$ of GAL4 VPl 6 protein $(\sim 4$ pmoles), and $125 \mu \mathrm{g}$ of nuclear extract protein containing RNA polymerase II CTD truncations. The nuclear extract concentration was in the linear range for selective transcription. The GAL4-VP16 concentration of $6 \mu \mathrm{g} / \mathrm{ml}$ was chosen because transcription activities reached maximal levels in all five nuclear extracts tested at this concentration. Purified wild-type yeast RNA polymerase II (100 ng) was added to the indicated reactions. The lane labeled - CTD Repeats shows the result obtained in the absence of nuclear extract. Labeled MspI DNA fragments of pBR322 were used as size markers. (D) RPB2 levels in each extract were approximated by Western blot analysis. Ten micrograms of each nuclear extract was subjected to SDS-PAGE, transferred to nitrocellulose, and probed with an anti-RPB2 polyclonal antibody (Buhler et al. 1980).
A

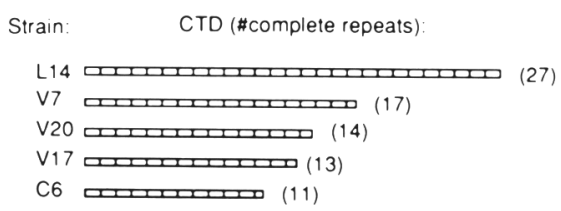

B

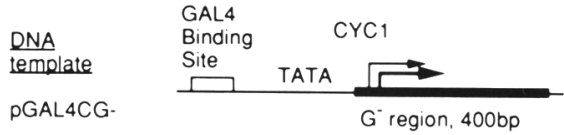

C

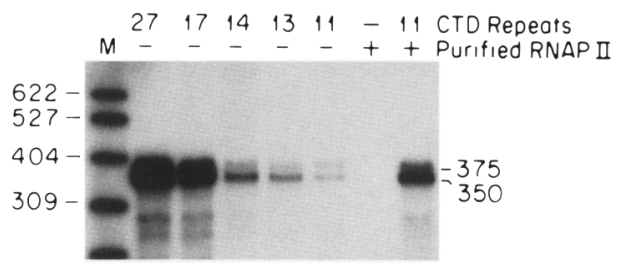

D

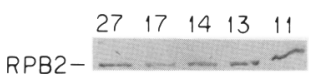


We investigated the levels of RNA polymerase II in the nuclear extracts used here by Western blot analysis. Because essentially all of the RNA polymerase II subunits that accumulate in cells are assembled into the complete enzyme, the levels of any one of the subunits reflect the levels of the whole enzyme (Kolodziej et al. 1990, 1991). The nuclear extracts used in these studies had similar amounts of intact RPB2, the second largest subunit (Fig. 1D). We also failed to detect differences in RNA polymerase II concentration among wild-type and CTD truncation mutant cells in several previous experiments (Nonet et al. 1987; Kolodziej 1991). Thus, CTD truncation does not affect RNA polymerase II concentration, indicating that the progressive loss in selective transcription observed with CTD truncation does not reflect reduced enzyme concentration.

\section{Restoration of selective transcription}

We investigated whether the defects in selective transcription observed in vitro are the result of a defect in RNA polymerase itself or the absence of other components essential for transcriptional activity. The addition of wild-type RNA polymerase to the nuclear extract containing RNA polymerase II with an 11-repeat CTD restored specific transcription to nearly wild-type levels (Fig. 1C). Thus, nuclear extracts from the CTD mutant cells are fully capable of supporting essentially normal levels of transcription in the presence of purified wildtype RNA polymerase II, suggesting that the truncated CTD in the mutant extracts is directly responsible for defects in selective transcription.

The addition of nuclear components other than RNA polymerase II did not remedy the selective transcription defect exhibited by extracts of CTD truncation mutants. RNA polymerase II can be inactivated in heat-treated nuclear extracts prepared from yeast $r p b 1-1$ cells; heattreated rpb1-1 extracts retain all of the components necessary for selective transcription when wild-type RNA polymerase II is added (Edwards et al. 1990). When such an $r p b 1-1$ heat-treated extract was added to extracts made from a CTD truncation mutant (11 repeats), no increase in selective transcription was observed /data not shown).

\section{Reduced responses to a second acidic activator}

To determine whether CTD truncation reduces the ability of RNA polymerase II to respond to acidic activators other than GAL4-VP16, we investigated the ability of nuclear extracts from a spectrum of CTD mutants to transcribe DNA containing GCN4-binding sites and a CYC1 TATA element in the presence of purified GCN4. The effect of CTD truncation on GCN4-dependent transcription was identical to that found with GAL4-VP16dependent transcription (Fig. 2).

These in vitro transcription experiments focus on the ability of the transcription apparatus to respond to single activating proteins. The progressive loss of GAL4-VP16 and GCN4-dependent in vitro transcripts that occurs

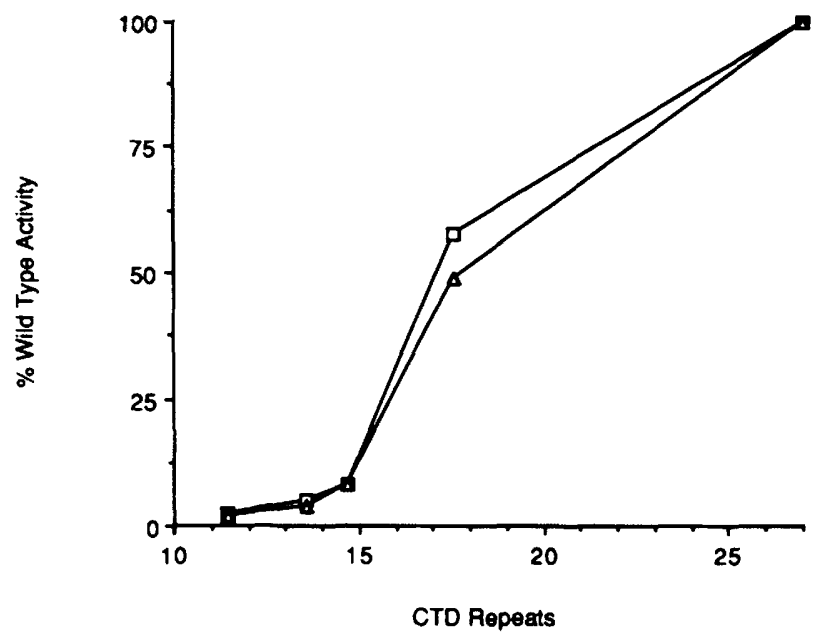

Figure 2. Effect of CTD truncation on trans-activator-dependent selective transcription. Amounts of GAL4-VP16-dependent $(\square)$ and GCN4-dependent $(\Delta)$ transcripts produced in nuclear extracts containing wild-type and mutant RNA polymerases were quantitated by counting gel slices from the experiment shown in Fig. 1 and from a similar experiment using GCN4 as the trans-activator and plasmid pGCN4CG $^{-}$DNA as template.

with CTD truncation is significantly greater than the reduction in GAL1O and HIS4 transcripts that has been described in vivo (Scafe et al. 1990). It is possible that the in vitro assay magnifies the defects associated with CTD truncation. However, it is also possible that the quantitatively greater loss of transcripts observed in vitro with progressive CTD truncation is the result of the difference in templates and factors employed in the in vitro and in vivo assays. The templates used in the in vitro assays described here were designed to investigate the response to the single activators GAL4-VP16 and GCN4. GAL4-VP16 was used in the in vitro assay, whereas GAL4 was the activator present in the in vivo assay (Scafe et al. 1990). Although only the GCN4-binding site was present in the template used in the in vitro assays described here, the entire HIS4 UAS was present in the template used in vivo (Scafe et al. 1990), and multiple factors can bind to this sequence (Arndt et al. 1987).

\section{CTD contribution seems limited to initiation}

The effect of RNA polymerase II CTD truncation on elongation was investigated in a promoter-independent transcription assay (Fig. 3). The promoter-independent RNA synthesis activities of each of the nuclear extracts was measured using heat-denatured salmon sperm DNA as template; the same extracts used in the selective transcription assays were used in this assay of elongation. RNA polymerase II activities in wild-type and in CTD mutant extracts did not differ by $>20 \%$ in this assay. Together with evidence that similar amounts of RNA polymerase II protein are found in each of the nuclear extracts, these results indicate that the promoter-independent specific activity of CTD mutant enzymes is 


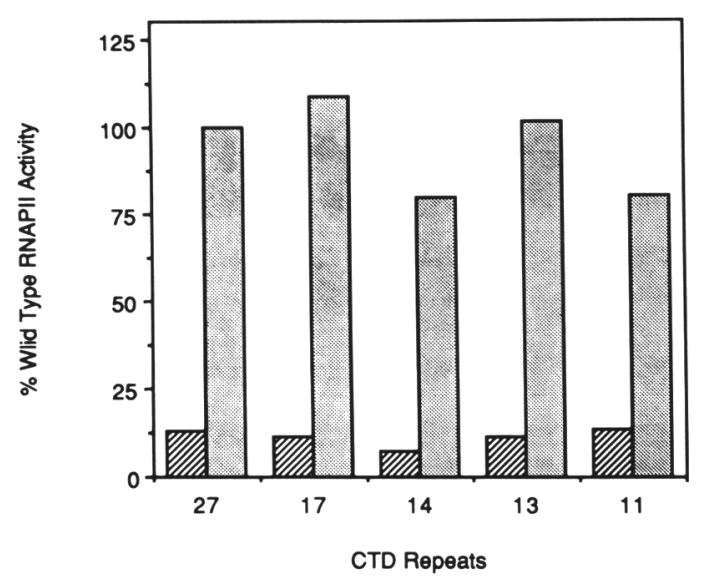

Figure 3. CTD truncation does not significantly alter promoter-independent transcription. Denatured salmon sperm DNA was used as template in an in vitro transcription reaction designed to measure nonspecific RNA synthesis by nuclear extracts containing RNA polymerase II with wild-type and truncated CTDs. Reactions were carried out in the presence (hatched bars) and absence (shaded bars) of $50 \mu \mathrm{g} / \mathrm{ml}$ of $\alpha$-amanitin. The results are expressed as percent of wild-type activity.

comparable to the wild type $\{0.35$ nmole of UMP incorporated in $10 \mathrm{~min} / \mathrm{mg}$ of extract protein). Because CTD truncation does not significantly affect promoterindependent RNA synthesis in vitro, we infer that CTD truncation does not affect elongation of the RNA transcript.

An RNA polymerase II transcription termination assay was used to assess the ability of RNA polymerase II CTD truncation mutants to recognize termination signals. RNA polymerase II was partially purified from wild-type cells and from the CTD truncation mutant C6, which retains 11 heptapeptide repeats. The termination assay involves RNA elongation on a DNA template containing a $3^{\prime}$ oligo(dC) extension and multiple sites at which wild-type mammalian and yeast RNA polymerase II terminate RNA synthesis in vitro (Reines et al. 1987; Edwards et al. 1991|. The results obtained with wild-type and CTD mutant RNA polymerases were similar in this assay (Fig. 4). Three major $\alpha$-amanitin-sensitive transcripts were observed; the largest is a runoff transcript, and the two smaller species are produced by termination or elongation arrest at two sites, TIa and TII. The fraction of transcripts that stop at these two sites was identical with wild-type and CTD mutant RNA polymerases; $\sim 40 \%$ of total transcripts stop at $\mathrm{Tla}$, and $20 \%$ stop at TII. Moreover, in time-course experiments with $3^{\prime}$ oligo(dC)-tailed templates, the wild-type and mutant RNA polymerases had indistinguishable elongation rates (data not shown). The absence of detectable defects in elongation or termination in these experiments suggests that the contribution of the CTD is limited to initiation.

\section{Transcription of nucleosome-assembled templates}

We wished to determine whether the effects of RNA polymerase II CTD truncation on GAL4-VP16-induced transcription would be visible on a more biologically relevant template, that is, one assembled into nucleosomes in vitro. Histones, nucleosome assembly factors, nuclear extracts, GAL4-VP16, and the same template DNA used in the experiment shown in Figure 1 were incubated together for $1 \mathrm{hr}$. During this incubation, the formation of the transcription initiation complex is in competition with nucleosomes for occupancy of the promoter. The reaction conditions were optimized to provide maximum assembly of the templates into nucleosomes. Subsequent to this incubation, transcription was initiated by the addition of nucleoside triphosphates.

A

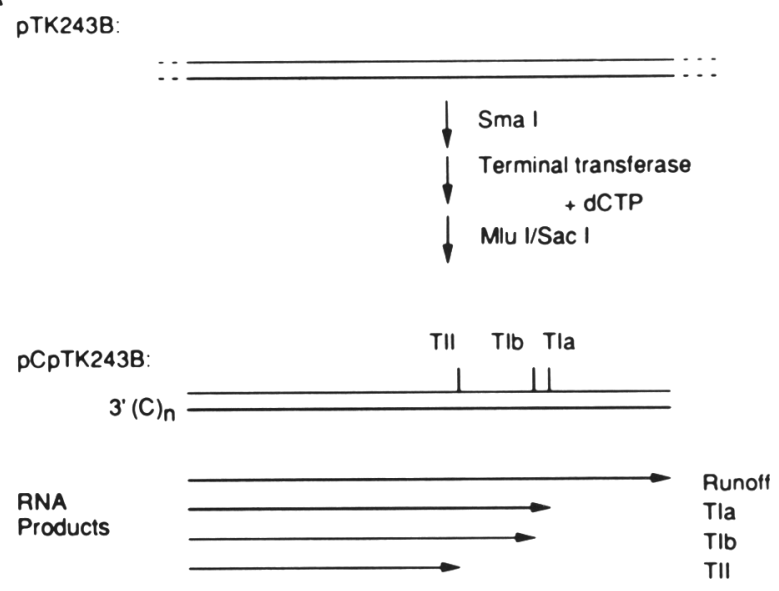

B

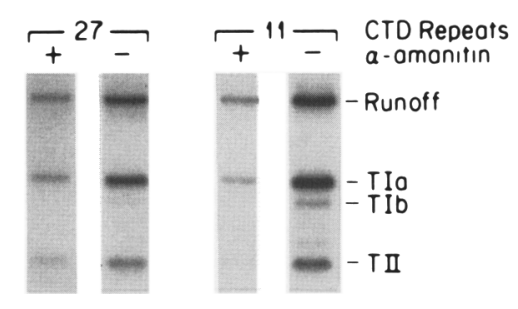

Figure 4. CTD truncation does not affect transcription termination in vitro. (A) Template pCpTK243B contains DNA from the human histone H3.3 gene, which has three sites (TIa, TIb, and TII) at which termination occurs in both yeast and mammalian transcription systems in vitro (Reines et al. 1987; Edwards et al. 1991). (B) Wild-type and CTD truncation mutant RNA polymerase II enzymes were partially purified from nuclear extracts using heparin-Sepharose chromatography (Edwards et al. 1990) and used to transcribe pCpTK243B in the presence or absence of $\alpha$-amanitin $(50 \mu \mathrm{g} / \mathrm{ml})$. RNA polymerase initiates at the single-stranded oligo(dC) end of the template and synthesizes transcripts of 326 nucleotides (runoff), 197 nucleotides (TIa), 182 nucleotides (TIb), and 138 nucleotides (TII) (27). Similar levels of wild-type and mutant RNA polymerase II activity, as measured with the poly $(\mathrm{rC})$ assay, were added to the termination assay, but wild-type RNA polymerase II appears to be slightly less active than the mutant enzyme in this assay. Nonetheless, both wild-type and mutant RNA polymerase II enzymes stop $\sim 40 \%$ of total transcripts at TIa and $20 \%$ at TII. 
CTD truncation has a significant effect on GAL4 VP16-dependent transcription of nucleosome-assembled template DNA (Fig. 5). As observed in previous experiments, progressive CTD truncation progressively reduces the levels of GAL4-VP16-dependent transcripts (to $53 \%$ of wild-type levels with 17 repeats, and to $8 \%$ with 13 repeats) in the absence of assembled histones. Under the conditions used in this experiment and in the absence of histones, an $\sim 400$-nucleotide transcript is observed in addition to the 350- and 375-nucleotide transcripts. This larger transcript has been observed by others (Lue et al. 1989; Woontner and Jaehning 1990). During nucleosome assembly and in the presence of wildtype RNA polymerase and GAL4-VP16, the levels of the 350- and 375-nucleotide transcripts are reduced approximately sixfold relative to the levels obtained in the absence of nucleosomes, and the 400-nucleotide transcript is not observed. In extracts containing RNA polymerase II with a CTD of 17 repeats, the level of specific transcripts is reduced to $26 \%$ of those obtained with wildtype enzyme. In extracts containing RNA polymerase II with a CTD of 14 repeats, those levels are reduced to $5 \%$ (not shown). No specific transcripts could be detected when RNA polymerase II contained only 13 or 11 hep-

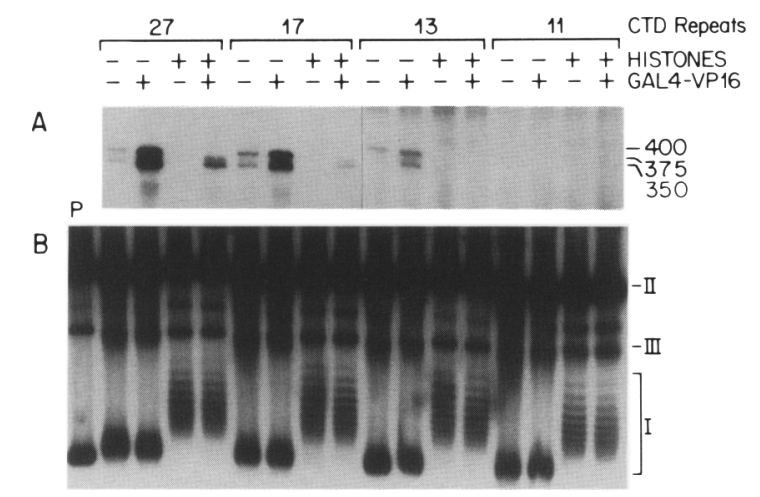

Figure 5. Progressive truncation of the RNA polymerase II CTD causes progressive loss of GAL4-VP16-stimulated transcription on a nucleosome-assembled template. $(A)$ Histones, nucleosome assembly factors, GAL4-VP16, and pGAL4CG template DNA were incubated with nuclear extracts containing wild-type and various CTD mutant RNA polymerases prior to initiating transcription by the addition of nucleoside triphosphates. The 350-, 375-, and 400-nucleotide transcripts are indicated. The 350- and 375-nucleotide-long transcripts are relevant to the assay, as the 400-nucleotide-long transcript is likely to be a portion of a readthrough transcript. The results shown for RNA polymerase II molecules with 27 and 17 repeats were from Kodak XRP-1 X-ray film exposed for 2 days, and those shown for RNA polymerase II with 13 and 11 repeats were from film exposed for 6 days. (B) Assembly reactions were performed exactly as in $A$ except that internally labeled template DNA was used. Following assembly reactions, each reaction mixture was analyzed on a $1 \%$ agarose, $40 \mu \mathrm{g} / \mathrm{ml}$ chloroquine TBE gel. (Lane $P$ ) The input labeled probe DNA. The positions of closed circular $(I)$, nicked circular $(I I)$, and linear $(I I I)$ templates are indicated.

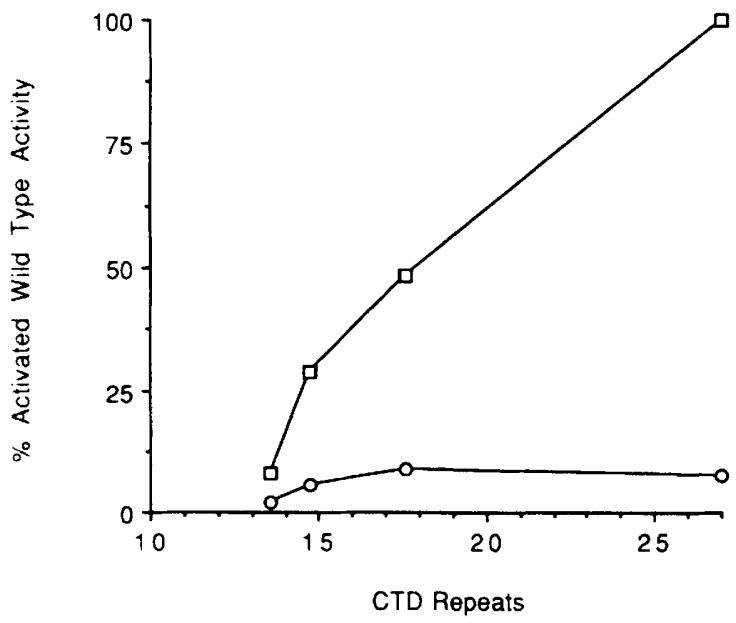

Figure 6. Progressive CTD truncation affects factor-dependent transcription more substantially than factor-independent transcription. Using nuclear extracts containing RNA polymerase II with wild-type and truncated CTDs, the relative levels of GAL4-VP16-dependent $(\square)$ and factor-independent $(O)$ transcripts were assayed under the conditions described for Fig. 5 in the absence of histones. Specific transcripts (350- and 375-nucleotide-long transcripts) were quantitated by using a Betascope 603 blot analyzer, which provided values significantly above background for transcripts that are not visualized easily in Fig. 5. The amount of transcript produced in extracts containing RNA polymerase CTDs with 11 repeats was too low to quantitate. The results of two experiments, one of which is shown in Fig. 5, were compiled to produce this diagram.

tapeptide repeats. Thus, CTD truncation results in substantially diminished factor-dependent transcription both from templates that have been assembled into nucleosomes and those that have not been so assembled.

The extent of nucleosome assembly was investigated to ensure that the results of the transcription assays are not due to differences in the assembly reactions. Nucleosome assembly was assayed by determining the degree of template supercoiling in the various assembly reactions used for transcription (Fig. 5B). Significant differences in the distribution of negative supercoiled species were not observed from one extract to another. There were, on average, 200-300 bp per nucleosome, as measured by the degree of positive supercoiling in the presence of chloroquine.

\section{Reduction of factor-independent transcription}

The effects of CTD truncation on factor-independent transcription could be analyzed in reactions that lacked nucleosomes; factor-independent transcription (i.e., basal transcription) was almost negligible with the nucleosome-assembled template, consistent with previous observations (Workman et al. 1991). In repeated experiments, we found that progressive CTD truncation does reduce the levels of factor-independent transcription, albeit to less of an extent than it reduces the levels of GAL4-VP16-dependent transcripts (Fig. 6). Thus, acti- 
vated transcription is more sensitive to CTD truncation than factor-independent transcription under these conditions. Factor-independent transcription was also reduced with CTD truncation under conditions used in previous experiments (i.e., under conditions used in the experiment shown in Fig. 1), but the levels of factorindependent transcripts were too low to accurately quantitate the extent of transcript loss with progressive truncation.

\section{Discussion}

We have investigated the function of the RNA polymerase II CTD by studying the effect of progressive CTD truncation on transcription initiation, elongation, and termination in vitro. We find that progressive truncation of the yeast RNA polymerase II CTD causes progressive loss of trans-activator-dependent transcription but has little effect on elongation or termination. RNA polymerase II is directly responsible for these defects, as specific transcription can be restored to a considerable degree in the defective nuclear extracts by adding purified wildtype enzyme. The reduced ability of RNA polymerase II CTD truncation mutants to respond to transcription activators was essentially identical for GAL4-VP16 and GCN4-stimulated transcription. These results indicate that the CTD contributes to the response of the transcription apparatus to activation signals from specific trans-activating proteins.

\section{CTD contribution to transcription initiation}

Experiments described here and elsewhere have implicated the CTD in transcription initiation at some promoters but have failed to detect any effect of CTD mutations on elongation or termination. The adverse effects of yeast RNA polymerase II CTD truncation in vivo are dependent on DNA upstream rather than downstream of the site of initiation (Scafe et al. 1990; Peterson et al. 1991). CTD-specific monoclonal antibodies that inhibit initiation in mammalian transcription reactions in vitro do not inhibit elongation (Laybourn and Dahmus 1989, 1990; Moyle et al. 1989; Thompson et al. 1989). We did not observe any defect in the ability of CTD mutant RNA polymerase II to elongate or terminate transcription in the assays described here.

Our results indicate that the CTD is involved in a rate-limiting step in the transcription initiation process that is regulated by GAL4-VP16. Several recent mechanistic studies argue that GAL4-VP16 may function by increasing the ability of the core transcription complex to compete with chromatin components for occupancy of the promoter (Croston et al. 1991; Workman et al. 1991|. This might be accomplished by a direct interaction between GAL4-VP16 and either TFIIB or TFIID (Stringer et al. 1990; Lin and Green 1991). Formation of a fully functional core complex requires association of RNA polymerase II, which interacts with the TFIIBTFIID complex that forms over the initiation region (Reinberg and Roeder 1987; Van Dyke et al. 1988; Bura- towski et al. 1989). We propose that the CTD plays an important role in the association of RNA polymerase with the core complex at certain promoters. Thus, truncation of the CTD would impair the ability of RNA polymerase II to form a fully functional core complex and would alter the effect that upstream activators have on the rate of formation of such a complex.

\section{Multiple factors affect CTD function}

By isolating dominant mutations that suppress the cold sensitivity of strains whose RNA polymerase CTDs contain 10 or 11 intact repeats, several genes have been identified that influence CTD function (Nonet and Young 1989; A. Koleske, C. Thompson and R.Young, unpubl.). The best characterized of these is $S R B 2$. The suppressing allele of this gene, $S R B 2-1$, is able to suppress the temperature sensitivity, cold sensitivity, and inositol auxotrophy of cells that contain CTDs with 10-12 repeats. In addition, SRB2-1 can rescue the lethal phenotype of a cell that has a CTD of only nine repeats. In contrast, deletion of the SRB2 gene causes cells with wild-type CTDs to become temperature sensitive, cold sensitive, and inositol auxotrophs, and these cells are unable to survive with CTDs containing 17 or fewer repeats. Thus, the SRB2 gene encodes a positive regulator of CTD function.

The removal of certain negative regulators from the cell can partially restore the ability of yeast RNA polymerase II with short CTDs to respond to activation signals at specific promoters in vivo (Peterson et al. 1991). The negative regulatory factor SIN1 represses transcription of the yeast $H O$ and INO1 genes. Deletion of the SIN1 gene partially restores the ability of RNA polymerase II CTD truncation mutants to respond to induction at the INO1 promoter and reduces the severity of the cold-sensitive phenotype of cells containing the RNA polymerase mutation.

Approximately half of the RNA polymerase molecules in rapidly growing yeast cells have a highly phosphorylated CTD (Kolodziej et al. 1990). Protein kinases have been isolated from yeast (Lee and Greenleaf 1989) and from mammalian cells (Cisek and Corden 1989) that can phosphorylate the CTD in vitro. The properties of the yeast enzyme indicate that it is distinct from previously described protein kinases and that its activity is highly cooperative or processive. Although the functional significance of phosphorylation is not yet clear, it has been suggested that CTD phosphorylation is involved in regulating the transition from initiation to elongation (Layborn and Dahmus 1989, 1990; Dahmus and Dynan 1991).

It seems reasonable that the sensitivity of various promoters to CTD truncation in vivo is influenced by both positive and negative regulatory proteins. The effects might vary with the strength and type of the upstream activator, as there is ample precedent for differential function of upstream transcriptional activators (Rougvie and Lis 1988; Tasset et al. 1990; Taylor and Kingston 1990). Certain upstream factors might regulate forma- 
tion of the core complex in a manner sensitive to CTD truncation while others might not. Moreover, the presence or absence of negative regulators such as SINl can clearly influence CTD dependence (Peterson et al. 1991). The CTD-dependent transcription system described here should facilitate further study of the role of specific factors in CTD function.

\section{Materials and methods}

\section{Yeast strains}

The Saccharomyces cerevisiae strains used for preparing nuclear extracts and their genotypes are listed in Table 1 (Nonet et al. 1987). L14 contains a wild-type RPB1 gene encoding a CTD of 27 complete heptapeptide repeats; V7 has $174 / 7$ repeats, V20 has $145 / 7$ repeats, V17 has $134 / 7$ repeats, and C6 has $113 / 7$ repeats. Fractions indicate the number of consensus amino acid residues that are retained in the last heptapeptide repeat.

\section{Plasmids}

Plasmid pGAL4CG- was kindly provided by Dr. R. Kornberg (Lue et al. 1989). Plasmid pGCN4CG ${ }^{-}$was constructed by inserting two GCN4-binding sites with oligonucleotides, convergently oriented, into pGAL4CG ${ }^{-}$between the PstI and Xhol sites to replace the GAL4-binding site. These GCN4-binding site oligonucleotides are 5'-GCGCTCGAGTGACTCACGTTTTTTTATCAGTCAC- $3^{\prime}$ and $5^{\prime}$-TCGAGTGACTGATAAAAAAACGTGAGTCACTCGAGCGCTGCA-3'. Plasmid pTK243B (Edwards et al. 1991), containing part of the human histone H3.3 intron sequence, was a generous gift of Dr. C. Kane. Plasmid pJL2 (Chasman et al. 1989), containing an IPTGinducible GAL4-VP16 gene, was obtained from Dr. M. Carey.

RNA polymerase, transcriptional activators, and nucleosome components

Purified yeast RNA polymerase II was kindly provided by Drs. A. Edwards and R. Kornberg (Edwards et al. 1990). The GAL4 VP16 fusion protein was expressed from pJL2 in Escherichia coli XA90 and partially purified by $0.2 \%$ polyethyleneimine and $35 \%$ ammonium sulfate precipitations (Chasman et al. 1989). This GAL4-VP16 protein was $>70 \%$ pure, as judged by Coomassie brilliant blue staining of protein in an SDS-polyacrylamide gel. GCN4 protein was kindly provided by Drs. C. Ampe and T. Steitz. Heat-treated egg supernatants containing nucleosome assembly factors were prepared according to Laskey et al. (1978). HeLa core histones (H2A, H2B, H3, and H4) were purified according to Stein and Mitchell (1988).

Table 1. Yeast strain list

\begin{tabular}{|c|c|}
\hline Name & Genotype \\
\hline L14 & 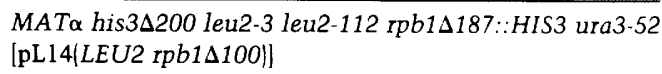 \\
\hline V7 & 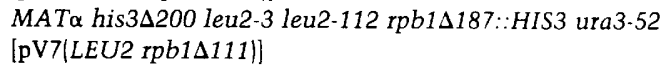 \\
\hline $\mathrm{V} 20$ & 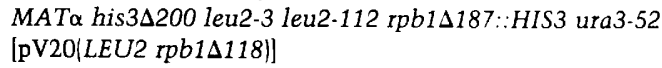 \\
\hline V17 & 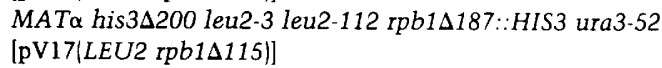 \\
\hline C6 & 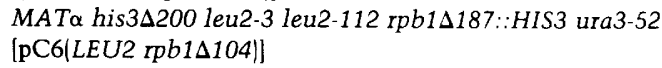 \\
\hline
\end{tabular}

\section{Nuclear extracts}

Nuclear extracts were prepared as described by Lue et al. (1990), with a few modifications. For spheroplasting, the cell pellet was resuspended in $100 \mathrm{ml}$ of YPD, $1 \mathrm{M}$ sorbitol, prior to Zymolyase digestion. After removing Zymolyase by washing, the spheroplasts were incubated for $60 \mathrm{~min}$ in YPD, $1 \mathrm{M}$ sorbitol. The extracts had final protein concentrations of $\sim 40 \mathrm{mg} / \mathrm{ml}$.

\section{Selective in vitro transcription}

The transcription reactions contained $50 \mathrm{mM}$ HEPES-KOH $/ \mathrm{pH}$ $7.31,100 \mathrm{~mm}$ potassium glutamate, $15 \mathrm{~mm} \mathrm{MgOAc}, 2.5 \mathrm{~mm}$ dithiothreitol, $5 \mathrm{~mm}$ EGTA, $4 \mathrm{~mm}$ phosphoenolpyruvate, $10 \%$ glycerol, $0.5 \mathrm{~mm}$ each of ATP and CTP, $5 \mu \mathrm{M}\left[\alpha^{-{ }^{32}} \mathrm{P}\right] \mathrm{UTP}(4000$ $\mathrm{cpm} / \mathrm{pmole}$ ), and 0.5 units of Inhibit-ACE $(5$ Prime-3 Prime, Inc.l. The total reaction volume $(25 \mu \mathrm{l})$ contained $0.25 \mu \mathrm{g}$ of template DNA (0.15 pmole), either $0.15 \mu \mathrm{g}$ of GAL4-VP16 protein ( $\sim$ pmoles) or $0.16 \mu \mathrm{g}$ of GCN4 protein (5 pmoles), and 125 $\mu \mathrm{g}$ of nuclear extract protein. A GAL4-VP16 concentration of 6 $\mu \mathrm{g} / \mathrm{ml}$ was chosen, because at this concentration, transcription activities reached maximal levels in all five nuclear extracts tested. The reaction mixture was incubated for $20 \mathrm{~min}$ at $24^{\circ} \mathrm{C}$. (Under these reaction conditions, transcriptional activity reaches its maximal level in $20 \mathrm{~min}$.) To the transcription reaction was added $100 \mu \mathrm{l}$ of $10 \mathrm{~mm}$ Tris $\mathrm{HCl} / \mathrm{pH} 7.6), 300 \mathrm{~mm}$ $\mathrm{NaCl}$, and $5 \mathrm{~mm}$ EDTA containing 40 units of RNase $\mathrm{T} 1$, and the RNase digestion was incubated for $10 \mathrm{~min}$ at $24^{\circ} \mathrm{C}$. To this solution was added $50 \mu \mathrm{l}$ of $10 \mathrm{mM}$ TrisCl $(\mathrm{pH} \mathrm{7.6),300} \mathrm{mM}$ $\mathrm{NaCl}$, and $5 \mathrm{~mm}$ EDTA containing $100 \mu \mathrm{g}$ of proteinase $\mathrm{K}$ and $3 \%$ SDS, and the mixture was incubated for $20 \mathrm{~min}$ at $30^{\circ} \mathrm{C}$. After phenol extraction and ethanol precipitation, the transcription products were fractionated on a $4 \%$ polyacrylamide $-7 \mathrm{M}$ urea gel. The gel was dried and autoradiographed on Kodak XRP-1 film for $6 \mathrm{hr}$ with an intensifying screen unless indicated otherwise. The methods and reagents used in these experiments are similar to those described by Lue et al. (1990) and Woontner and Jaehning (1990). To quantitate the levels of transcripts, gel slices containing RNA were excised from the polyacrylamideurea gels following autoradiography, and the amounts of labeled RNA were determined by scintillation counting. All of the transcription experiments were performed at least twice to ensure reproducibility.

\section{Nonselective in vitro transcription}

RNA polymerase II activity in nuclear extracts containing wildtype or CTD truncation mutant enzyme was assayed in $25-\mu 1$ reactions containing $50 \mathrm{~mm}$ Tris- $\mathrm{HCl}(\mathrm{pH} 8.0) ; 6 \mathrm{mM} \mathrm{MnCl} \mathrm{M}_{2} 2.5$ $\mathrm{mM}$ dithiothreitol; $0.5 \mathrm{~mm}$ each of ATP, CTP, and GTP; $20 \mu \mathrm{M}$ $\left[5,6{ }^{3} \mathrm{H}\right] \mathrm{UTP} \quad(2000 \mathrm{cpm} / \mathrm{pmole}) ; 25 \mu \mathrm{g}$ of heat-denatured salmon sperm DNA $\left(90^{\circ} \mathrm{C}, 10 \mathrm{~min}\right)$; and $40 \mu \mathrm{g}$ of nuclear extract protein. Transcription reactions were performed in the presence and absence of $50 \mu \mathrm{g} / \mathrm{ml}$ of $\alpha$-amanitin. The methods and reagents used in this experiment are similar to those described by Valenzuela et al. (1978). The concentration of extract proteins $(\sim 1.6 \mathrm{mg} / \mathrm{ml})$ is in the linear range for transcriptional activity as tested in a protein titration experiment. After incubating at $24^{\circ} \mathrm{C}$ for $20 \mathrm{~min}$, the entire reaction was spotted onto a filter disk (no. 30 glass microfiber filter), which was prespotted with $100 \mu \mathrm{l}$ of $10 \%$ trichloroacetic acid (TCA) and $100 \mathrm{~mm}$ sodium pyrophosphate. The filter was washed three times with $5 \mathrm{ml}$ of $5 \%$ TCA and $50 \mathrm{~mm}$ sodium pyrophosphate, and once with $5 \mathrm{ml}$ of $95 \%$ ethanol, by using a Millipore apparatus. The amount of label incorporated into RNA was determined using a scintilla- 
tion counter. This experiment was performed twice to ensure reproducibility.

\section{Partial purification of RNA polymerase by heparin-Sepharose} column

The nuclear extracts could not be used directly in the transcription termination assay, apparently as a result of interference by oligo(dC)-binding proteins in nuclear extracts (Dr. C. Kane, pers. comm.). To remedy this problem, both wild-type RNA polymerase II and a CTD mutant RNA polymerase II (from C6 cells) were partially purified by a heparin-Sepharose CL-6B column (1.5 $\times$ A3 cm; Pharmacia), as described by Edwards et al. (1990). Proteins from nuclear extracts prepared from 1 liter of cell culture were precipitated with ammonium sulfate $169 \%$ saturation) from buffer C (Lue et al. 1990). The pellets were dissolved in buffer A $[50 \mathrm{~mm}$ Tris- $\mathrm{HCl}(\mathrm{pH} 7.9), 1 \mathrm{~mm}$ EDTA, $0.5 \mathrm{~mm}$ dithiothreitol, $10 \mathrm{~mm} \mathrm{NaF}, 10 \mathrm{~mm}$ sodium pyrophosphate, $10 \%$ glycerol, $2 \mathrm{~mm}$ benzamidine, $2 \mu \mathrm{M}$ pepstatin A, $0.6 \mu \mathrm{M}$ leupeptin, $2 \mu \mathrm{g} / \mathrm{ml}$ of $N$-tosyl-L-lysine chloromethyl ketone, $1 \mathrm{~mm}$ phenylmethylsulfonyl fluoride] and dialyzed against buffer A for 2 $\mathrm{hr}$ before application to a heparin-Sepharose column. The nonspecific transcriptional activity of the partially purified RNA polymerases was measured with a poly(rC) assay (Ruet et al. 1978). A unit of activity is defined as 1 nmole of GMP incorporated into acid-insoluble RNA per minute. The enzyme partially purified from $\mathrm{L} 14$ cells had a specific activity of 0.23 $\mathrm{U} / \mathrm{mg}$, and that from $\mathrm{C} 6$ cells had a specific activity of $1.0 \mathrm{U} / \mathrm{mg}$. The partially purified wild-type RNA polymerase II preparation contained more RNA polymerase I and III activity than the mutant RNA polymerase II preparation, as measured by $\alpha$-amanitin sensitivity in both the poly(rC) assay and the transcription termination assay.

\section{Transcription termination assay}

Transcription termination was assayed by using as template pCpTK243B, containing a single-stranded extension on the $3^{\prime}$ end, according to Edwards et al. (1991). The plasmid DNA was cleaved with SmaI, extended at the $3^{\prime}$ ends with dCTP and terminal transferase (Ratliff, Inc.), and digested with SacI and MluI to produce template DNA with one $3^{\prime}$ oligo(dC) terminus. RNA polymerase initiates at the single-stranded oligo(dC) end of the DNA fragment and synthesizes transcripts of 326 (runoff), 197 (TIa), 182 (TIb), and 138 nucleotides (TII). The buffer contained $50 \mathrm{~mm}$ Tris-acetate $(\mathrm{pH} 8.0), 100 \mathrm{~mm}$ ammonium acetate, $5 \mathrm{~mm}$ magnesium acetate, $5 \%$ glycerol, $6 \mathrm{~mm}$ spermidine, $1 \mathrm{~mm}$ DTT, and 1.0 units of Inhibit-ACE (5 Prime-3 Prime, Inc.). DNA template (100 ng) and partially purified wild-type or CTD mutant RNA polymerase II (0.016 units) was incubated at $30^{\circ} \mathrm{C}$ in the presence or absence of $\alpha$-amanitin $(50 \mu \mathrm{g} / \mathrm{ml})$ for $5 \mathrm{~min}$. Transcription was initiated by the addition of $\left[\alpha{ }^{-32} \mathrm{P} \mid \mathrm{CTP}\right.$ to $0.13 \mu \mathrm{M}(800 \mathrm{Ci} / \mathrm{mmole})$, and ATP, GTP, and UTP to $0.8 \mathrm{mM}$ in a total volume of $30 \mu \mathrm{l}$. After $\mathrm{l}$ min of incubation at $30^{\circ} \mathrm{C}, 10$ volumes of chasing buffer $10.1 \mathrm{mM}$ CTP, $100 \mu \mathrm{g} / \mathrm{ml}$ of heparin in reaction buffer) was added, and the incubation was allowed to continue for $1 \mathrm{~min}$ to permit completion of already initiated transcripts. The reaction was stopped by the addition of EDTA and tRNA to $10 \mathrm{mM}$ and $200 \mu \mathrm{g} / \mathrm{ml}$, respectively. The RNA products were analyzed on a $6 \%$ polyacrylamide $-7 \mathrm{M}$ urea gel and quantitated as described above. By taking aliquots at various time points after adding chasing buffer, we found that a single round of transcription is completed by 1 min. Further incubation did not change the patterns or the intensities of RNA bands. Similar levels of wild-type and mutant RNA polymerase II activity, as measured with the poly(rC) assay, were added to the termination assay, but the wild-type RNA polymerase II preparation appears to be slightly less active than the mutant preparation in termination assay. Because the partially purified wild-type RNA polymerase II preparation had a lower specific activity than the mutant enzyme, we suspect that the larger amount of protein added with the wild-type preparation may have been slightly inhibitory, given the sensitivity of this assay to contaminating protein from nuclear extracts.

\section{Nucleosome assembly}

Nucleosome assembly mixtures containing heat-treated Xenopus egg supernatants, histones, and topoisomerase I were pre pared as described previously (Workman et al. 1990). Ten microliters of the nucleosome assembly mixture, with or without $400 \mathrm{ng}$ of histones, was mixed with $200 \mathrm{ng}$ of template DNA, $125 \mu \mathrm{g}$ of nuclear extract, and $0.15 \mu \mathrm{g}$ of GAL4-VP16 protein, where present, to a volume of $20 \mu \mathrm{l}$ in selective transcription buffer (except the buffer contained $1.1 \mathrm{~mm} \mathrm{MgOAc} \mathrm{m}_{2}$. Assembly reactions proceeded for $60 \mathrm{~min}$ at $30^{\circ} \mathrm{C}$. Transcription of the nucleosome-assembled template was started by the addition of $5 \mu \mathrm{l}$ of a solution containing nucleotides and other components necessary to bring final buffer conditions to those described above for the selective in vitro transcription assay. The extent of nucleosome assembly on template DNA was assayed using internally labeled plasmid DNA as described by Workman et al. (1991).

\section{Acknowledgments}

We thank David Chao, Jeffry Corden, Arno Greenleaf, Ira Herskowitz, Caroline Kane, Anthony Koleske, Craig Peterson, Charles Scafe, and Craig Thompson for helpful discussions and comments on the manuscript, and Andrew Buermeyer and Peggy Farnham for communicating results prior to publication. We are grateful to Shelly Berger, Michael Carey, Peter Flanagan, Caroline Kane, Roger Kornberg, and Jerry Workman for plasmids and advice, Janine Huet and Andre Sentenac for RPB2 antibody, Christophe Ampe and Tom Steitz for generous gifts of GCN4 protein, and Al Edwards for yeast RNA polymerase II. This work was supported by grants from the U.S. Public Health Service, Hoechst AG, and the Damon Runyon-Walter Winchell Cancer Fund. R.A.Y. is a Burroughs Wellcome Scholar.

The publication costs of this article were defrayed in part by payment of page charges. This article must therefore be hereby marked "advertisement" in accordance with 18 USC section 1734 solely to indicate this fact.

\section{References}

Allison, L.A. and J. Ingles. 1989. Mutations in RNA polymerase II enhance or suppress mutations in GAL4. Proc. Natl. Acad. Sci. 86: 2794-2798.

Allison, L.A., M. Moyle, M. Shales, and J. Ingles. 1985. Extensive homology among the largest subunits of eukaryotic and prokaryotic RNA polymerases. Cell 42: 599-610.

Allison, L.A., J.K.-C. Wong, V.D. Fitzpatrick, M. Moyle, and J. Ingles. 1988. The C-terminal domain of the largest subunit of RNA polymerase II of Saccharomyces cerevisiae, Drosophila melanogaster, and mammals: A conserved structure with an essential function. Mol. Cell Biol. 8: 321-329.

Arndt, Kim T., C. Styles, and G.R. Fink. 1987. Multiple global regulators control HIS4 transcription in yeast. Science 237: 874-880.

Bartolomei, M.S., N.F. Halden, C.R. Cullen, and J.L. Corden. 
1988. Genetic analysis of the repetitive carboxy-terminal domain of the largest subunit of mouse RNA polymerase II. Mol. Cell Biol. 8: 330-339.

Bird, D.M. and D.L. Riddle. 1989. Molecular cloning and sequencing of ama-l, the gene encoding the largest subunit of Caenorhabditis elegans RNA polymerase II. Mol. Cell Biol. 10: 5562-5564.

Buhler, J.-M., J. Huet, K.E. Davies, A. Sentenac, and P. Fromageot. 1980. Immunological studies of yeast nuclear RNA polymerases at the subunit level. J. Biol. Chem. 255:9949-9954.

Buratowski, S., S. Hahn, L. Guarente, and P.A. Sharp. 1989. Five intermediate complexes in transcription initiation by RNA polymerase II. Cell 56: 549-561.

Cadena, D.L. and M.E. Dahmus. 1987. Messenger RNA synthesis in mammalian cells is catalyzed by the phosphorylated form of RNA polymerase II. I. Biol. Chem. 262: 1246812474.

Chao, D.M. and R.A. Young. 1991. Tailored tails and transcription initiation: The carboxyl terminal domain of RNA polymerase II. Gene Expression 1: 1-4.

Chasman, D.I., J. Leatherwood, M. Carey, M. Ptashne, and R.D. Kornberg. 1989. Activation of yeast polymerase II transcription by herpesvirus VP16 and GAL4 derivatives in vitro. Mol. Cell Biol. 9: 4746-4749.

Cisek, L.J. and J.L. Corden. 1989. Phosphorylation of RNA polymerase by the murine homologue of the cell-cycle control protein cdc2. Nature 339: 679-684.

Corden, J.L. 1990. Tails of RNA polymerase II. Trends Biochem. Sci. 15: 383-387.

Corden, J.L., D.L. Cadena, J.M. Ahearn Jr., and M.E. Dahmus. 1985. A unique structure at the carboxyl terminus of the largest subunit of eukaryotic RNA polymerase II. Proc. Natl. Acad. Sci. 82: 7934-7938.

Croston, G.E., L.A. Kerrigan, L.M. Lira, D.R. Marshak, and J. Kadonaga. 1991. Sequence-specific antirepression of histone Hl-mediated inhibition of basal RNA polymerase II transcription. Science 251: 643-649.

Dahmus, M.E. and W.S. Dynan. 1991. Phosphorylation of RNA polymerase II as a transcriptional regulatory mechanism. In Transcriptional regulation (ed. S. McKnight and K. Yamamoto). Cold Spring Harbor Laboratory Press, Cold Spring Harbor, New York. (In press.)

Dietrich, M.A., J.P. Prenger, and T.J. Guifoyle. 1990. Analysis of the genes encoding the largest subunit of RNA polymerase II in Arabidopsis and soybean. Plant Mol. Biol. 15: 207-223.

Edwards, A.M., S.A. Darst, W.J. Feaver, N.E. Thompson, R.R. Burgess, and R.D. Kornberg. 1990. Purification and lipidlayer crystallization of yeast RNA polymerase II. Proc. Natl. Acad. Sci. 87: 2122-2126.

Edwards, A.M., C.M. Kane, and R.D. Kornberg. 1991. Two dissociable subunits of yeast RNA polymerase II stimulate the initiation of transcription at a promoter in vitro. $/$. Biol. Chem. 266: 71-75.

Falkenburg, D., B. Dworniczak, D. Faust, and E.K.F. Bautz. 1987. RNA polymerase II of Drosophila: Relation of its $140,000 \mathrm{M}_{\mathrm{r}}$ subunit to the $\beta$ subunit of Escherichia coli RNA polymerase. I. Mol. Biol. 195: 929-937.

Kim, W.-Y., and M.E. Dahmus. 1989. The major late promoter of adenovirus -2 is accurately transcribed by RNA polymerase IIO, IIA and IIB. I. Biol. Chem. 264: 3169-3176.

Kolodziej, P.A. 1991. "Investigations of RNA polymerase II subunit structure and assembly," Ph.D. thesis. MIT, Cambridge, MA.

Kolodziej, P.A., N. Woychik, S.-M. Liao, and R.A. Young. 1990. RNA polymerase II subunit composition, stoichiometry, and phosphorylation. Mol. Cell Biol. 10: 1915-1920.
Lasky, R.A., B.M. Honda, A.D. Mills, and J.T. Finch. 1978. Nucleosomes are assembled by an acidic protein which binds histones and transfers them to DNA. Nature 275: 416-420.

Laybourn, P.J. and M.E. Dahmus. 1989. Transcription-dependent structural changes in the C-terminal domain of mammalian RNA polymerase subunits IIa/o. I. Biol. Chem. 264: 6693-6698.

1990. Phosphorylation of RNA polymerase IIA occurs subsequent to interaction with the promoter and before the initiation of transcription. J. Biol. Chem. 265: 13165-13173.

Lee, J.M. and A.L. Greenleaf. 1989. A protein kinase that phosphorylates the C-terminal repeat domain of the largest subunit of RNA polymerase II. Proc. Natl. Acad. Sci. 86: 3624 3628 .

Lin, Y.-S. and M.R. Green. 1991. Mechanism of action of an acidic transcriptional activator in vitro. Cell 64: 971-981.

Lue, N.F., P.M. Flanagan, K. Sugimoto, and R.D. Kornberg. 1989. Initiation by yeast RNA polymerase II at the adenoviral major late promoter in vitro. Science 246: 661-664.

Lue, N.F., P.M. Flanagan, R.J. Kelleher III, A.M. Edwards, and R.D. Kornberg. 1990. RNA polymerase II transcription in vitro. Methods Enzymol. 194: 545-550.

Moyle, M., J.S. Lee, W.F. Anderson, and C.J. Ingles. 1989. The C-terminal domain of the largest subunit of RNA polymerase II and transcription initiation. Mol. Cell Biol. 9: 57505753.

Nonet, M. and R.A. Young. 1989. Intragenic and extragenic suppressors of mutations in the heptapeptide repeat domain of Saccharomyces cerevisae RNA polymerase II. Genetics 123: 715-724.

Nonet, M., D. Sweetser, and R.A. Young. 1987. Functional redundancy and structural polymorphism in the largest subunit of RNA polymerase II. Cell 50: 909-915.

Peterson, C.L., W. Kruger, and I. Herskowitz. 1991. A functional interaction between the C-terminal domain of RNA polymerase II and the negative regulator SIN1. Cell 64: 11351143.

Reinberg, D. and R.G. Roeder. 1987. Factors involved in specific transcription by mammalian RNA polymerase II. $J$. Biol. Chem. 262: 3310-3321.

Reines, D., D. Wells, M.J. Chamberlin, and C.M. Kane. 1987. Identification of intrinsic termination sites in vitro for RNA polymerase II within eukaryotic gene sequences. $J$. Mol. Biol. 196: $299-312$.

Rougvie, A.E. and I.T. Lis. 1988. The RNA polymerase II molecule at the $5^{\prime}$ end of the uninduced $h s p 70$ gene of $\mathrm{D}$. melanogaster is transcriptionally engaged. Cell 54: 795-804.

Ruet, A., A. Sentenac, and P. Fromageot. 1978. A specific assay for yeast RNA polymerase in crude cell extracts. Eur. J. Biochem. 90: 325-330.

Scafe, C., D. Chao, J. Lopes, J.P. Hirsch, S. Henry, and R.A. Young. 1990. RNA polymerase II C-terminal repeat influences response to transcriptional enhancer signals. Nature 347: 491-494.

Stein, A. and M. Mitchell. 1988. Generation of different nucleosome spacing periodicities in vitro: Possible origins of cell type specificity. I. Mol. Biol. 203:1029-1043.

Stringer, K.F., C.J. Ingles, and J. Greenblatt. 1990. Direct and selective binding of an acidic transcriptional activator domain to the TATA-box factor TFIID. Nature 345: 783-786.

Tasset, D., L. Tora, C. Fromental, E. Scheer, and P. Chambon. 1990. Distinct classes of transcriptional activating domains function by different mechanisms. Cell 62: 1177-1187.

Taylor, I.C.A. and R.E. Kingston. 1990. Factor substitution in a human HSP7O gene promoter: TATA-dependent and TATAindependent interactions. Mol. Cell Biol. 10: 165-175. 
Liao et al.

Thompson, N.E., T.H. Steinberg, D.B. Aronson, and R.R. Burgess. 1989. Inhibition of in vivo and in vitro transcription by monoclonal antibodies prepared against wheat germ RNA polymerase II that react with the heptapeptide repeat of eukaryotic RNA polymerase II. I. Biol. Chem. 264: 1151111520.

Valenzuela, P., G. Bell, F. Weinberg, and W.J. Rutter. 1978. Isolation and assay of eukaryotic DNA-dependent RNA polymerases. Methods Cell Biol. 19: 1-26.

Van Dyke, M.W., R.G. Roeder, and M. Sawadogo. 1988. Physical analysis of transcription preinitiation complex assembly on a class II gene promoter. Science 241: 1335-1338.

Woontner, M. and J.A. Jaehning. 1990. Accurate initiation by RNA polymerase II in a whole cell extract from Saccharomyces cerevisiae. J. Biol. Chem. 265: 8979-8982.

Workman, J.L., R.G. Roeder, and R.E. Kingston. 1990. An upstream transcription factor, USF (MLTF), facilitates the formation of preinitiation complex during in vitro chromatin assembly. EMBO /. 9: 1299-1308.

Workman, J.L., I.C.A. Taylor, and R.E. Kingston. 1991. Activation domains of stably bound GAL4 derivatives alleviate repression of promoters by nucleosomes. Cell 64: 533-544.

Zehring, W.A., J.M. Lee, J.R. Weeks, R.S. Jokerst, and A.L. Greenleaf. 1988. The C-terminal repeat domain of RNA polymerase II largest subunit is essential in vivo but is not required for accurate transcription initiation in vitro. Proc. Natl. Acad. Sci. 85: 3698-3702. 


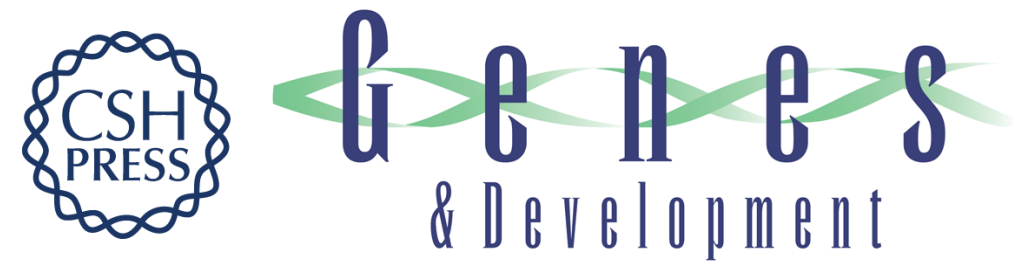

\section{RNA polymerase II carboxy-terminal domain contributes to the response to multiple acidic activators in vitro.}

S M Liao, I C Taylor, R E Kingston, et al.

Genes Dev. 1991, 5:

Access the most recent version at doi:10.1101/gad.5.12b.2431

References This article cites 48 articles, 25 of which can be accessed free at:

http://genesdev.cshlp.org/content/5/12b/2431.full.html\#ref-list-1

License

Email Alerting

Service

Receive free email alerts when new articles cite this article - sign up in the box at the top right corner of the article or click here.

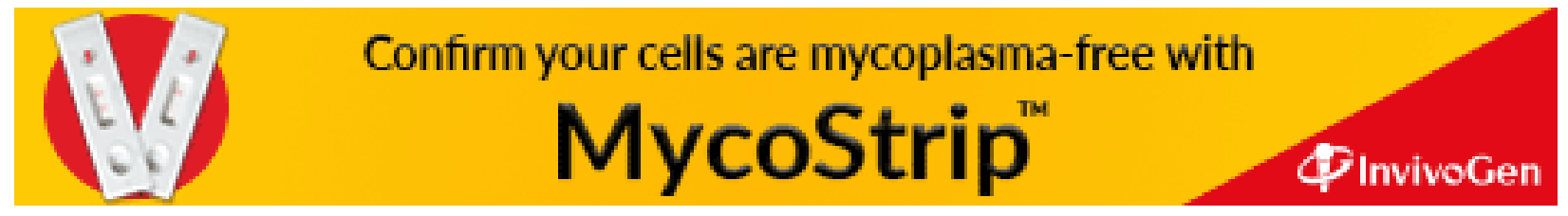

